\title{
Enhanced PMN response in chronic bronchitis and community- acquired pneumonia
}

\author{
A. Strassburg*, D. Droemann", G. van Zandbergen", H. Kothe*, K. Dalhoff*
}

Enhanced PMN response in chronic bronchitis and community-acquired pneumonia. A. Strassburg, D. Droemann, G. van Zandbergen, H. Kothe, K. Dalhoff. (C)ERS Journals Ltd 2004.

ABSTRACT: Chronic bronchitis is a frequent underlying disease in communityacquired pneumonia (CAP). It is unclear to what extent an impaired or exaggerated innate immune response contributes to disease manifestations and severity.

To assess the role of neutrophil activation and recruitment during acute pneumonic episodes, peripheral polymorphonulcear neutrophil (PMN) activation, chemotactic activity, interleukin-8 (CXCL-8) and CXCL-8 receptor (CXCR) expression and apoptosis rate were evaluated in CAP patients with and without chronic bronchitis. In addition, the expression of CXCRs and CXCL-8 was assessed on pulmonary neutrophils in chronic bronchitis patients to compare the activation of the chemokine system in different compartments. CAP severity was assessed by the simplified acute physiology score II and the prognosis of disease was assessed by the pneumonia severity index (PSI).

An increased chemotactic activity of PMN from chronic bronchitis patients with CAP was found, which was not related to the expression of CXCRs. In addition, a decreased apoptosis rate of PMN was observed. Chemotactic activity was related to the PSI. Comparison of peripheral and pulmonary PMN revealed enhanced CXCL-8 levels and a decreased CXCR expression in the lung.

In conclusion, neutrophil function in patients with chronic bronchitis and communityacquired pneumonia is characterised by an increased chemotactic activity combined with a decreased apoptosis rate. The downregulation of interleukin-8 receptors in the pulmonary compartment deserves further investigation.

Eur Respir J 2004; 24: 772-778.
*III. Dept of Medicine, and "Institute for Medical Microbiology, University of Luebeck, Luebeck, and ${ }^{\#}$ Research Centre Borstel, Borstel, Germany.

Correspondence: A. Strassburg

III. Dept of Medicine

University of Luebeck

Ratzeburger Allee 160

23538 Luebeck

Germany

Fax: 494515006014

E-mail: alan.strassburg@gmx.de

Keywords: Community-acquired pneumonia chemotaxis

chronic bronchitis

interleukin-8

neutrophil function

Received: December 172003

Accepted after revision: July 132004
Community-acquired pneumonia (CAP) remains a common cause of morbidity and mortality. An important risk factor for the development of CAP is the presence of serious comorbidities, including chronic bronchitis.

The natural history of chronic bronchitis is characterised by acute exacerbations that carry an increased mortality risk [1]. Moreover, chronic obstructive pulmonary disease (COPD) is the most common underlying disease in patients with CAP requiring hospitalisation. Little is known regarding the influence of chronic bronchitis on pulmonary host defences and the reasons for the enhanced susceptibility to bacterial infection in this population.

The central component of the innate immune response to bacterial challenge is activation and recruitment of neutrophils. The phagocytic capacity of neutrophils and natural killer cell function has been shown to be decreased in patients with chronic bronchitis [2]. Moreover, in mice with emphysema and streptococcal pneumonia, an impaired inflammatory response was observed [3]. In contrast, enhanced effector functions have been described in stable patients with chronic bronchitis, including increased chemotaxis of polymorphonuclear neutrophils (PMN) [4] and an enhanced chemotactic activity of sputum supernatants [5]. Finally, a recent study demonstrated enhanced expression of the neutrophil chemokines interleukin-5, CXCL-8 and CXC receptors in the bronchial mucosa of COPD patients with acute exacerbations [6].
A network of pathways co-ordinates the recruitment of neutrophils to the sites of inflammation. Among the CXC chemokines, interleukin-8 (CXCL-8) is the most potent mediator affecting neutrophil mobility and function. CXCL8 has been shown to be an important trigger of chemotactic activity in the lungs of patients with chronic bronchitis [7, 8]. CXCL-8 is produced not only by alveolar macrophages but also by epithelial cells, stromal cells and the immigrating neutrophils themselves [9]. There are two CXCL-8 receptors (CXCR-1 and CXCR-2) that are expressed in high density on PMN [10]. CXCR-1 binds CXCL-8 and granulocyte chemotactic protein-2 with moderate affinity, whereas CXCR-2 binds a range of CXC chemokines, including CXCL-1, CXCL-5, CXCL-7 and CXCL-8 with high affinity [11]. After binding CXCL-8, the receptors are internalised. The impact of ligand-induced endocytosis and subsequent re-expression of CXCRs for migration of neutrophils is under debate [12].

Upon chemokine exposure, neutrophils are activated, including a change of cell shape, integrin upregulation, respiratory burst, and degranulation. After transmigration and phagocytosis of pathogens, this process is terminated by apoptosis or cell necrosis, which also is modulated among other mediators by CXCL-8 [13]. Recent studies suggest that in pneumonia without underlying lung disease neutrophil apoptosis is delayed, leading to an increased burden of inflammatory cells in the airways [14]. 
The current authors investigated whether patients with chronic bronchitis during pneumonic episodes show an impaired or increased neutrophil chemotaxis and inflammatory response as compared to patients without underlying diseases. To this end, activation parameters, chemotaxis, chemokine and chemokine receptor expression and apoptosis rates were evaluated on circulating neutrophils in CAP patients with and without chronic bronchitis. Additionally, in a subgroup of patients, the changes systemic PMN undergo during transmigration into the pulmonary compartment were analysed by simultaneous assessment of surface markers, including CXCR1 and CXCR2, on cells obtained by bronchial minilavage (ML).

\section{Methods}

\section{Study design}

Within $24 \mathrm{~h}$ after admission, venous blood was drawn from 24 CAP patients. The study population consisted of two groups. Group 1 was composed of 16 patients with CAP and chronic bronchitis. Prior to admission, three patients had been treated with systemic glucocorticoids $(<20 \mathrm{mg}$ prednisone $\cdot \mathrm{day}^{-1}$ ) for $>1$ week, and five patients were pre-treated with antimicrobial agents for a maximum of 5 days. For the diagnosis of chronic bronchitis, a history of increased mucus production with productive cough over $\geqslant 3$ months per year for $\geqslant 2$ succeeding yrs was required. For the diagnosis of pneumonia, a new or progressive infiltrate on the chest radiograph was required, together with two or more of the following criteria: pulmonary symptoms, such as cough, chest pain or auscultatory findings; fever or hypothermia; positive blood or ML culture; or $>5 \%$ intracellular bacteria in Gram's stains of ML samples. Nine patients (six males and three females; five smokers and four nonsmokers; median age 65.7 yrs) were bronchoscopically evaluated within the first $24 \mathrm{~h}$ after admission because of treatment failure or for exclusion of other conditions.

Group 2 was composed of eight CAP patients without comorbidities. Three patients had been treated with antimicrobial agents prior to admission for a maximum of 5 days.
Demographic data of the study population are summarised in table 1 .

This study was approved by the ethical committee of the Medical University of Luebeck, Luebeck, Germany, and all patients were included after informed consent.

\section{Cell purification from peripheral blood}

PMN were isolated by Percoll density gradient centrifugation, which has been proved to cause minimal preactivation of the cells [18]. Briefly, the blood was layered on Histopaque $\mathbb{R} 1119$ (Sigma, Taufkirchen, Germany) and centrifugated for $20 \mathrm{~min}$ at $900 \times g$. The PMN-rich interface was collected and washed once in RPMI 1640 (SeromedBiochrom, Berlin, Germany), and cells were further fractionated on a discontinous Percoll (Amersham Pharma, Freiburg, Germany) gradient consisting of layers with densities of $1.105 \mathrm{~g} \cdot \mathrm{mL}^{-1}(85 \%), 1.1 \mathrm{~g} \cdot \mathrm{mL}^{-1}(80 \%), 1.093 \mathrm{~g} \cdot \mathrm{mL}^{-1}$ $(75 \%), 1.087 \mathrm{~g} \cdot \mathrm{mL}^{-1}(70 \%)$ and $1.081 \mathrm{~g} \cdot \mathrm{mL}^{-1}(65 \%)$. After centrifugation for $20 \mathrm{~min}$ at $2,000 \times \mathrm{g}$, the interface between the $80 \%$ and $85 \%$ Percoll layers was collected and washed twice. All procedures were carried out at room temperature. The purity of PMN was always $>99 \%$. The viability of cells was $>98 \%$ as assessed by trypan blue (Sigma) exclusion. Supernatants were harvested and stored at $-80^{\circ} \mathrm{C}$ for cytokine measurements.

\section{Bronchoscopy}

Bronchoscopy was performed within $24 \mathrm{~h}$ after enrolment in nine patients of group 1 according to standard conditions. ML was performed in the most severely affected area with instillation of $5-10 \mathrm{~mL}$ of $0.9 \% \mathrm{NaCl}$. The $\mathrm{ML}$ fluid was immediately re-aspirated; recovery was $60-120 \%$. The lavage fluid was diluted to a final volume of $50 \mathrm{~mL}(1: 10)$ and vortexed until homogenous in appearance. To eliminate remaining mucus, the sample was filtrated through four layers of gauze. After centrifugation at $400 \times g$ for $10 \mathrm{~min}$, the pellet was re-suspended in PBS. Total cell count was enumerated and cells were differentiated, counting a minimum

Table 1.-Demographic data of the study population

\begin{tabular}{|c|c|c|c|}
\hline & CAP with chronic bronchitis & CAP without chronic bronchitis & p-value \\
\hline Sex M/F & $10 / 6$ & $6 / 2$ & 0.45 \\
\hline Age yrs & $69.13 \pm 12.44$ & $54.12 \pm 17.88$ & 0.027 \\
\hline Smokers/nonsmokers & $11 / 5$ & $2 / 6$ & 0.055 \\
\hline Pack yrs & $45.91 \pm 16.4$ & $11 \pm 5.66$ & \\
\hline CPIS [15] & $3.69 \pm 2.02$ & $4.71 \pm 1.8$ & 0.26 \\
\hline PSI [16] & $96.9 \pm 20.43$ & $68 \pm 30.16$ & 0.018 \\
\hline SAPS II [17] & $21.43 \pm 4.75$ & $20.75 \pm 7.3$ & 0.73 \\
\hline $\mathrm{PMN} \cdot \mathrm{nL}^{-1}$ & $12.29 \pm 4.07$ & $10.58 \pm 4.29$ & 0.51 \\
\hline $\mathrm{CRP} \mathrm{mg} \cdot \mathrm{L}^{-1}$ & $128.3 \pm 90.79$ & $187.29 \pm 102.15$ & 0.20 \\
\hline $\begin{array}{l}\text { Antibiotic treatment } \\
\text { before admission yes/no }\end{array}$ & $5 / 11$ & $3 / 5$ & 0.55 \\
\hline Microbiology & $\begin{array}{c}\text { Streptococcus pneumoniae } 2 \\
\text { Moraxella catarrhalis } 1 \\
\text { Haemophilus influenzae } 3 \\
\text { Chlamydia pneumoniae } 1\end{array}$ & $\begin{array}{l}\text { Streptococcus pneumoniae } 2 \\
\text { Moraxella catarrhalis } 1\end{array}$ & \\
\hline Comorbidities & $\begin{array}{c}\text { Congestive heart failure } 1 \\
\text { Arterial hypertension } 5 \\
\text { Coronary heart disease } 4 \\
\text { Anaemia } 1 \\
\text { Malnutrition } 1\end{array}$ & & \\
\hline
\end{tabular}

Data are presented as mean \pm SD or $\mathrm{n}$. CAP: community-acquired pneumonia; CIPS: clinical pulmonary infection score; PSI: pneumonia severity index (FINE-Score); SAPS II: new simplified acute physiology score; PMN: polymorphonuclear neutrophils; CRP: C-reactive protein. 
of 600 cells of a cytocentrifuge smear (Cytospin II; Shandon, Frankfurt, Germany) stained with Wright-Giemsa solution. Viability was determined by trypan blue exclusion, and the sample was diluted to a concentration of $1 \times 10^{6}$ viable cells $\cdot \mathrm{mL}^{-1}$.

\section{Flow cytometry}

Surface markers and apoptosis were determined by using three-colour flow cytometry as described previously [14]. Briefly, flow cytometric analysis was performed on a fluorescence-activated cell sorter scan analyser (Becton Dickinson Bioscience, Mountain View, CA, USA), and data acquisition and analysis were performed with CellQuest software (Becton Dickinson). Each measurement contained $\geqslant 10,000$ cells in the granulocyte population, as determined by forward/orthogonal light scattering, CD45 expression, and missing CD14 and human leukocyte antigen-DR expression. Detection kits and antibodies against the following epitopes were used: fluorescein isothiocyanate (FITC)-labelled: deoxynucleotidyl transferase-mediated dUTP-biotin nick-end labelling (APO-Direct ${ }^{\mathrm{TM}}$-Kit; PharMingen, Heidelberg, Germany), CD66b, phycoerythrin-labelled: isotype control, CD11b (complement receptor 3), CD16 (FcyIII receptor), CXCR-1 and CXCR-2, all purchased from PharMingen (Heidelberg, Germany). Two distinct populations were detected after deoxynucleotidyl transferase-mediated dUTP nick-end labelling (TUNEL) staining, the one with the higher fluorescence intensity representing apoptotic cells. Because no bimodal distribution was found in the expression of surface markers, this was calculated as relative mean fluorescence intensity (rMFI; monoclonal antibody/corresponding isotype control).

\section{Intracellular flow cytometry}

For intracellular staining, purified peripheral neutrophils or neutrophils from ML samples were fixed with 4\% paraformaldehyde for $10 \mathrm{~min}$ at room temperature. After washing in PBS, the cell pellet was resuspended in $100 \mu \mathrm{L}$ PBS, containing $0.1 \%$ Saponin and $1 \%$ HEPES (permeabilisation buffer). The cells were incubated with FITC-labelled anti-CXCL-8 monoclonal antibody $\left(0.1 \mu \mathrm{g} \cdot \mathrm{mL}^{-1}\right)$ or FITC-conjugated control isotype $\left(0.1 \mu \mathrm{g} \cdot \mathrm{mL}^{-1}\right)$ for $20 \mathrm{~min}$ at $4^{\circ} \mathrm{C}$ in the dark. The cells were washed with $1 \mathrm{~mL}$ permeabilisation buffer and then resuspended in PBS $0.5 \%$ BSA before analysis. To exclude nonspecific binding, anti-CXCL-8 monoclonal antibodies were pre-incubated for $15 \mathrm{~min}$ with recombinant human CXCL-8 $\left(10 \mu \mathrm{g} \cdot \mathrm{mL}^{-1}\right)$ or with an excess of an irrelevant cytokine $\left(50 \mu \mathrm{g} \cdot \mathrm{mL}^{-1}\right)$ before cell staining (data not shown). Samples were then analysed by flow cytometry as described above. A total of 15,000 events were acquired per sample. Thresholds were set on control stains. Expression of intracellullar CXCL-8 was calculated as rMFI (monoclonal antibody/corresponding isotype control).

\section{Chemotaxis assay}

Chemotaxis assays were performed with purified peripheral PMN. RPMI 1640 medium with or without CXCL-8 was placed in the lower wells of a 24-well transwell plate (Costar, Bodenheim, Germany) in a volume of $600 \mu \mathrm{L}$. CXCL-8 $(1 \mathrm{nM})$ proved to be an optimal concentration in preliminary experiments (data not shown) and is comparable to IL-8 concentrations found in the sputum of patients with chronic inflammatory airway diseases [8]. PMN were suspended at
$5 \times 10^{6}$ cells $\cdot \mathrm{mL}^{-1}$ in medium and added to the upper chamber in a volume of $100 \mu \mathrm{L}$. A polycarbonate filter with $3-\mu \mathrm{M}$ pore size separated the two chambers. The chambers were incubated for $60 \mathrm{~min}$ at $37^{\circ} \mathrm{C}$ in a humified atmosphere containing $5 \% \mathrm{CO}_{2}$. The number of cells migrated into the lower chamber was determined by a glucuronidase assay [19]. Briefly, cells in the lower compartment were lysed in $1 \%$ Triton X-100, and glucuronidase enzymatic activity was measured by using p-nitrophenyl-glucuronide (Sigma) as a substrate. The number of migrated cells was calculated from a standard curve obtained with lysates of known numbers of PMN. All assays were performed in duplicate. In all chemotaxis experiments a chemotactic index (CI) was calculated by dividing the number of migrated cells towards CXCL8 through the number of cells migrated in medium alone.

\section{Statistics}

Nonparametric statistics were used throughout the study. Data are given as mean \pm SD unless otherwise stated. The Mann-Whitney U-test was used for comparison of data from CAP patients with and without chronic bronchitis, and the Wilcoxon signed-rank test was used for comparison of paired samples. For analysis of correlations, Spearman's rank correlation test was performed. For analysis of categorical variables, Fisher's exact test was used.

To test whether the association between the CI and a history of chronic bronchitis remains stable after adjustment for relevant confounders, a linear regression analysis was performed taking the $\mathrm{CI}$ as dependent variable. Age, sex, smoking status, CAP severity and the history of chronic bronchitis were chosen as independent variables. This study reports $\beta$ coefficients as measures of association and p-values as measures of stability. A p-value $<0.05$ was considered to be significant.

\section{Results}

\section{Chemotactic activity of peripheral neutrophils}

The CI of PMN was significantly increased in CAP patients with chronic bronchitis (group 1) compared to patients without underlying diseases (group 2): $11.34 \pm 5.39$ versus $6.36 \pm 0.77$, respectively; $\mathrm{p}<0.002$ (fig. 1). This finding was not

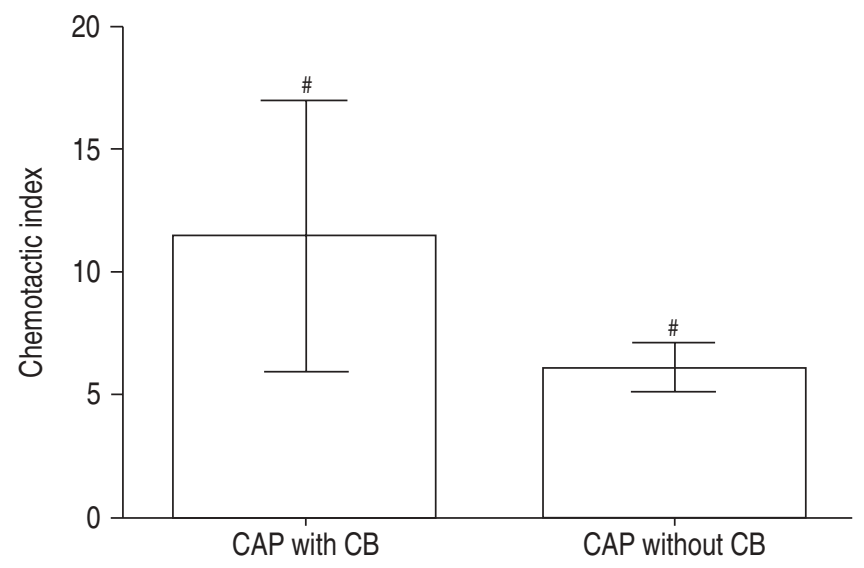

Fig. 1.-Chemotactic index (CI) of purified blood polymorphonuclear neutrophils towards $1 \mathrm{nM}$ CXCL-8. Data are presented as mean \pm SD. $\mathrm{CI}$ is shown from community-acquired pneumonia (CAP) patients with chronic bronchitis (CB) $(n=16)$ and without CB $(n=8)$. \#: $\mathrm{p}<0.002$. 


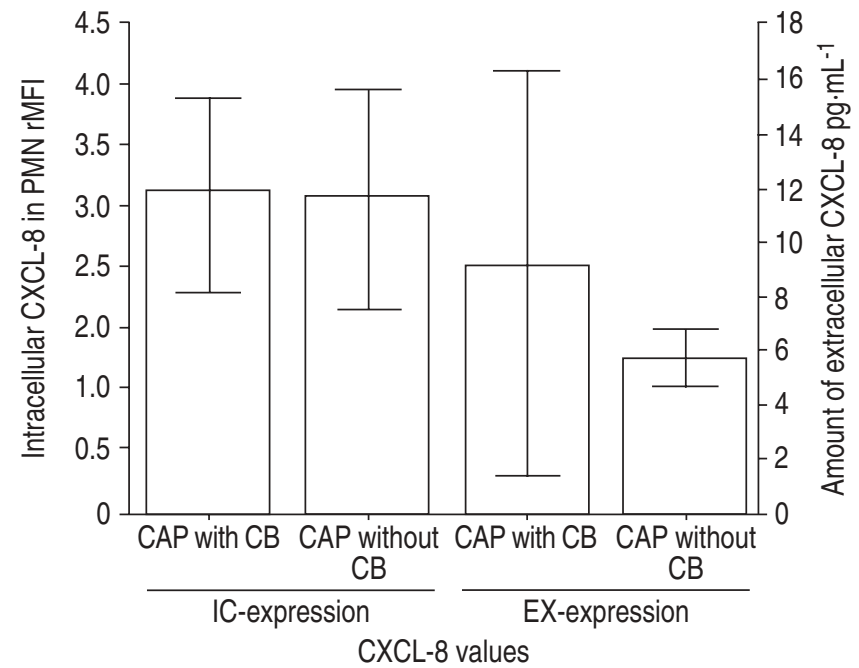

Fig. 2. - Flow cytometric expression (relative mean fluorescence intensity: rMFI) of intracellular (IC) CXCL-8 in peripheral polymorphonuclear neutrophils (PMN) and serum levels of extracellular (EX) CXCL-8 (pg $\left.\cdot \mathrm{mL}^{-1}\right)$ from community-acquired pneumonia (CAP) patients with chronic bronchitis $(\mathrm{CB})(\mathrm{n}=16)$ and without $\mathrm{CB}(\mathrm{n}=8)$.

significantly influenced by pre-treatment with glucocorticoids or with antimicrobial agents (data not shown).

To test whether the expression of CXCL-8 receptors on neutrophils accounts for this difference, CXCR-1 and CXCR2 surface levels were evaluated by flow cytometry. There was no difference in the expression of CXCR-1 and CXCR-2 on systemic cells from both patient groups (table 2). In addition, no differences in the intracellular expression or serum concentrations of CXCL-8 were observed, although the latter were tendentially elevated in patients with chronic bronchitis $\left(8.42 \pm 7.0 \mathrm{pg} \cdot \mathrm{mL}^{-1}\right.$ versus $5.23 \pm 1.5 \mathrm{pg} \cdot \mathrm{mL}^{-1} ; \mathrm{p}=\mathrm{NS}$, fig. 2). To assess the role of conditions that may influence the CI, a multivariate analysis, including age, sex, smoking habits and disease severity measured by the new simplified acute physiology score (SAPS II), was performed. Table 3 shows that only chronic bronchitis was significantly associated with the CI. Combining all CAP patients, the pneumonia severity index correlated with the $\mathrm{CI}(\mathrm{r}=0.62, \mathrm{p}<0.002)$.

\section{Activation markers and polymorphonuclear neutrophil apoptosis}

Regarding activation markers, PMN of CAP patients with chronic bronchitis showed modest increases of the

Table 2.-Flow cytometric expression (relative mean fluorescence intensity: $\mathrm{rMFI}$ ) of surface molecules, CXCL-8 receptors and activation markers on peripheral polymorphonuclear leukocytes \begin{tabular}{llll}
\hline Variable & $\begin{array}{l}\text { CAP patients with } \\
\text { chronic bronchitis }\end{array}$ & $\begin{array}{c}\text { CAP patients without } \\
\text { chronic bronchitis }\end{array}$ & p-value
\end{tabular}

\begin{tabular}{llll}
\hline rMFI & & & \\
CXCR-1 & $37.88 \pm 10.16$ & $30.81 \pm 7.34$ & NS \\
CXCR-2 & $68.03 \pm 32.17$ & $61.11 \pm 29.53$ & NS \\
CD66b & $19.57 \pm 3.68$ & $17.78 \pm 6.37$ & NS \\
CD62L & $18.25 \pm 7.24$ & $23.59 \pm 14.74$ & NS \\
CD11b & $22.57 \pm 12.38$ & $19.97 \pm 13.88$ & NS \\
\hline
\end{tabular}

Data are presented as mean \pm SD. CAP: community-acquired pneumonia; CXCR: CXC chemokine receptors. NS: nonsignificant.
Table 3.-Multivariate analysis for factors influencing the chemotactic index of peripheral polymorphonuclear leukocytes

\begin{tabular}{lcc}
\hline Condition & $\beta$-coefficient & p-value \\
\hline Chronic bronchitis & 0.662 & 0.026 \\
Age & 0.130 & 0.725 \\
Sex & 0.149 & 0.442 \\
Smoking history & -0.432 & 0.070 \\
SAPS II [17] & 0.053 & 0.864
\end{tabular}

SAPS II: simplified acute physiology score II.

surface expression of CD11b and CD66b and a decreased expression of CD62L indicating enhanced cell activation (table 2). However, these differences were not statistically significant.

As compared to CAP patients without underlying diseases, the patients with chronic bronchitis showed a significant decrease of systemic PMN apoptosis $(0.98 \pm 0.76 \%$ versus $3.15 \pm 1.97 \%$, respectively; $\mathrm{p}<0.02$, fig. 3 ). This finding was independent of pre-treatment with glucocorticoids or with antimicrobial agents (data not shown).
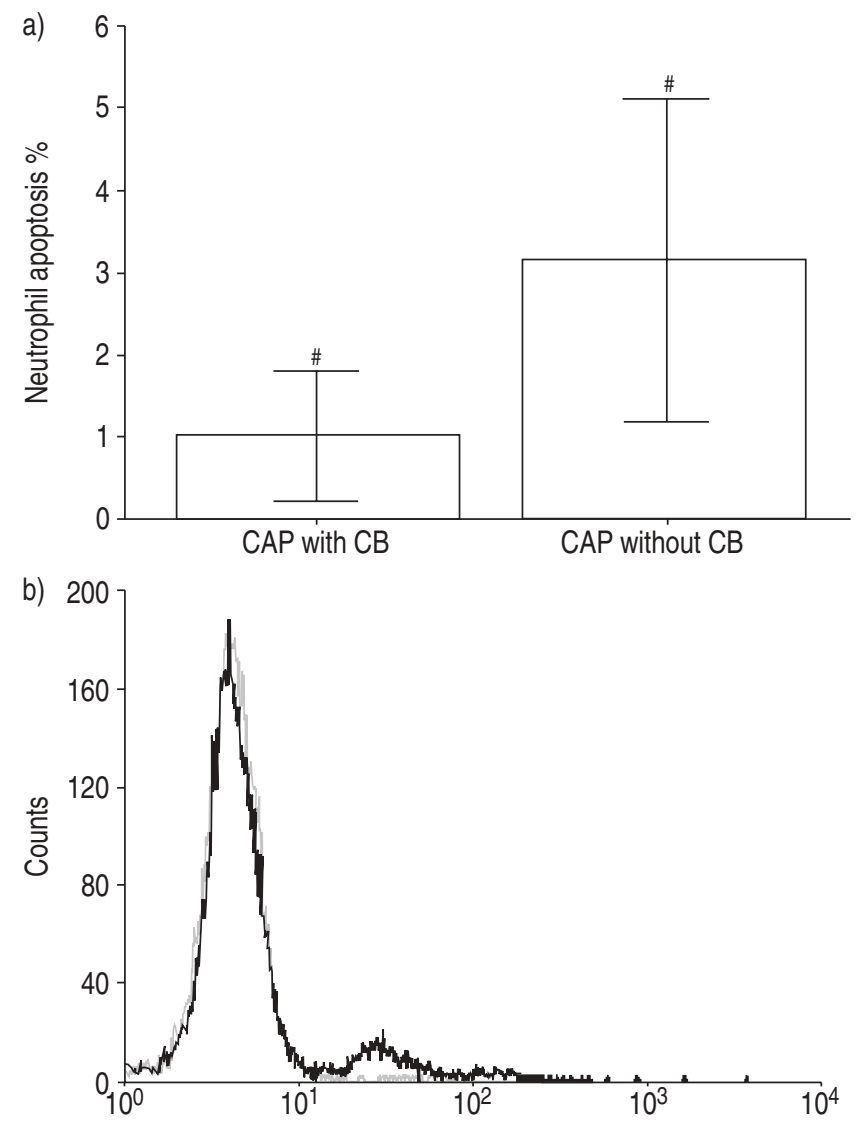

Fig. 3. - a) Flow cytometric expression of deoxynucleotidyl transferase-mediated dUTP nick-end labelling indicating apoptosis rate $(\%)$ of peripheral polymorphonuclear leukocytes (PMN) from community-acquired pneumonia (CAP) patients with chronic bronchitis (CB) $(n=16)$ and without CB $(n=8)$. b) Representative histogram. The darker line represents the signal from peripheral PMN of CAP patients without CB. The lighter line represents the signal from peripheral PMN of CAP patients with CB. ${ }^{\#}: \mathrm{p}<0.02$. 

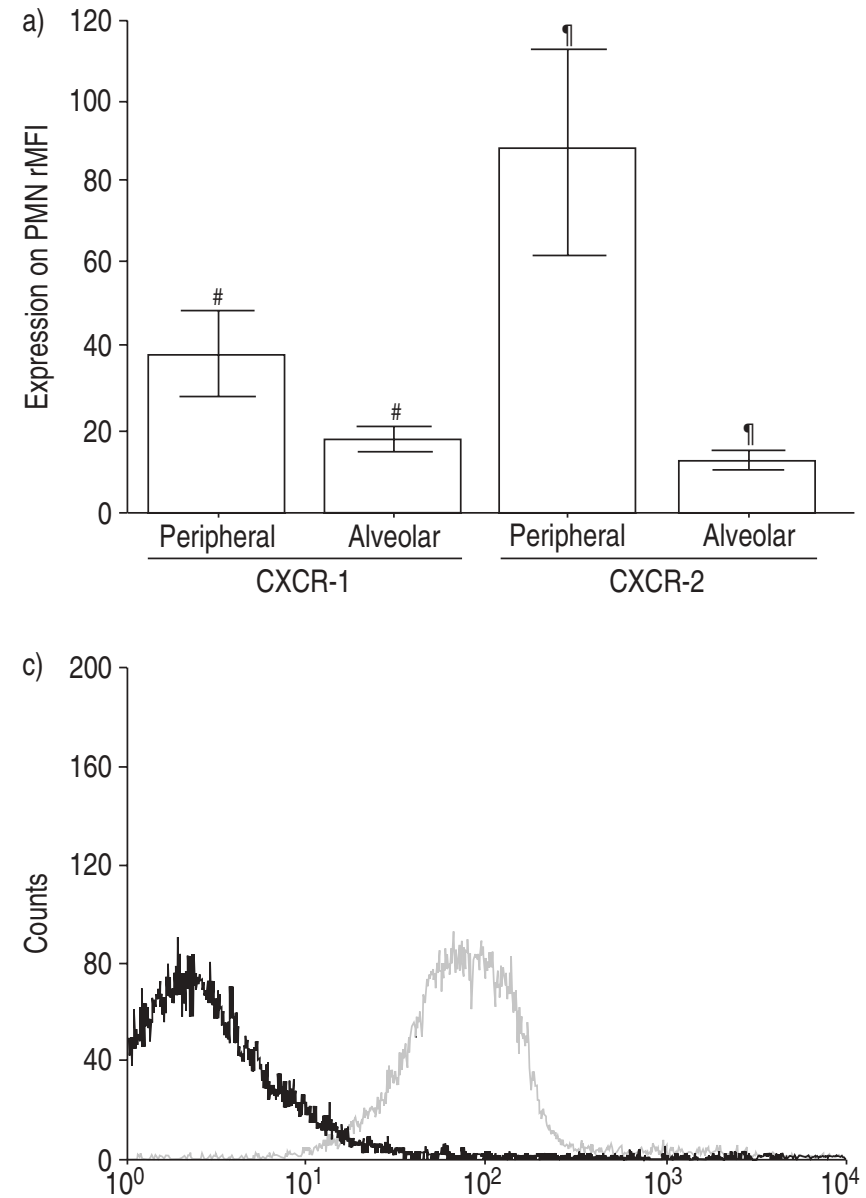

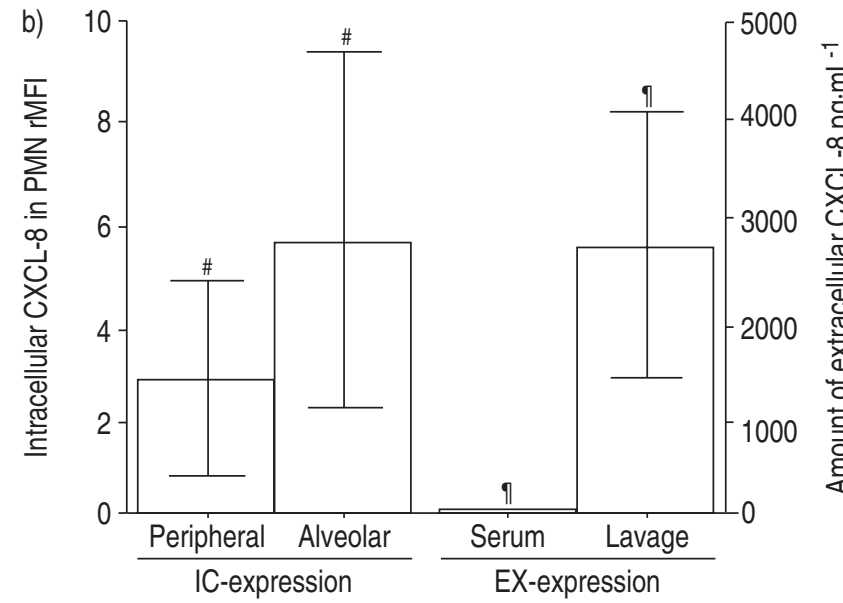

CXCL-8 values

d)

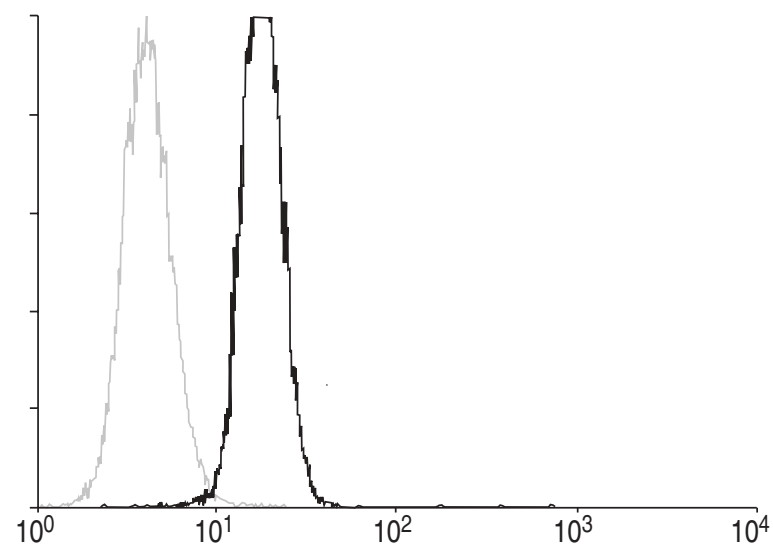

Fig. 4.-a) Flow cytometric expression (relative mean fluorescence intensity: rMFI) of CXCR-1 and CXCR-2 on peripheral and alveolar polymorphonuclear neutrophils (PMN) from community-acquired pneumonia (CAP) patients with chronic bronchitis (n=9). b) Flow cytometric expression of intracellular (IC) CXCL-8 in peripheral and alveolar PMN and extracellular (EX) serum and bronchoalveolar lavage fluid levels of CXCL-8 from CAP patients with chronic bronchitis $(n=9)$. c) A representative histogram of the surface expression of CXCR-1 on alveolar and peripheral PMN from a patient. The lighter line represents the signal from peripheral PMN, the darker line the signal from alveolar PMN. d) A representative histogram of the intracellular expression signal of CXCL-8 in peripheral and alveolar PMN from a patient. The lighter line represents the signal from peripheral PMN, the darker line the signal from alveolar PMN. ${ }^{\#}: \mathrm{p}<0.02 ;{ }^{\natural}: \mathrm{p}<0.05$.

Differences between neutrophilic inflammation in the pulmonary and systemic compartment

In the subgroup of CAP patients with chronic bronchitis who underwent ML, a highly significant downregulation of CXCR expression in pulmonary PMN compared to systemic cells was observed (CXCR-1: 8.32 \pm 4.24 rMFI versus $31.58 \pm$ 9.39 rMFI; CXCR-2: 5.99 \pm 4.53 rMFI versus $83.01 \pm 8.84$ rMFI, respectively; $\mathrm{p}<0.02$, fig. 4 ). This finding was accompanied by inverse differences of CXCL-8 levels (intracellular expression in pulmonary and systemic PMN: $5.53 \pm 3.53$ rMFI versus $2.77 \pm 2.02$ rMFI, $\mathrm{p}<0.05$; ML fluid versus serum concentrations: $2,965 \pm 1,302.75 \mathrm{pg} \cdot \mathrm{mL}^{-1}$ versus $11.15 \pm 9.177 \mathrm{pg} \cdot \mathrm{mL}^{-1}$; $\mathrm{p}<0.05$ ). In addition, the surface expression of CD11b and CD66b was increased on pulmonary PMN compared to systemic PMN $(p<0.05$, table 4). There was an inverse relationship between the expression of $\mathrm{CD} 11 \mathrm{~b}$ and intracellular CXCL-8 on pulmonary PMN ( $\mathrm{r}=-0.75, \mathrm{p}<0.05)$.

\section{Discussion}

There are few data available concerning the innate immune response of patients with chronic bronchitis during welldefined episodes of acute respiratory infection. In the present study, an enhanced chemotactic activity and prolonged survival of peripheral neutrophils was observed compared to CAP controls without underlying diseases, suggesting that an exaggerated inflammatory response is characteristic for chronic bronchitis during pneumonic episodes. The enhanced chemotactic activity may even be underestimated, since patients of the chronic bronchitis group were significantly older and former studies on the chemotactic response of PMN towards complement and other chemotactic agents suggest that, with ageing, recruitment of granulocytes into infected tissue is impaired [20-22]. However, multivariate analysis

Table 4. - Flow cytometric expression (relative mean fluorescence intensity: rMFI) of surface molecules and activation markers on peripheral and alveolar polymorphonuclear neutrophils (PMN)

\begin{tabular}{lccc}
\hline Variable & Peripheral PMN & Alveolar PMN & p-value \\
\hline rMFI & & & \\
CD66b & $22.35 \pm 10.71$ & $58.26 \pm 25.84$ & $<0.05$ \\
CD62L & $25.06 \pm 10.12$ & $1.51 \pm 1.1$ & $<0.02$ \\
CD11b & $27.02 \pm 14$ & $56.5 \pm 30.45$ & $<0.05$ \\
\hline
\end{tabular}

Data are presented as mean \pm SD. 
showed no influence of age on the chemotactic activity in the present study.

These data are in line with a previous study showing enhanced migration of PMN to formyl-methionyl-leucyl phenylalanine (fMLP) in patients with stable COPD [4]. Whereas that observation could be explained by increased expression of fMLP-receptors on PMN from smokers with and without COPD [23], in this study, with CXCL-8 being used as chemotactic stimulus, no correlation between the expression of CXC receptors and the chemotactic index was demonstrable in vitro. Previous authors studying patients with sepsis found significant decreases in the surface expression of CXCR-2 [24] in association with a marked deficit in the chemotactic response to $\mathrm{CXC}$ chemokines. This difference may be due to the more pronounced intravascular inflammation in sepsis compared to CAP. The observation in the current study that the chemotactic activity correlates significantly with the pneumonia severity index in CAP patients indicates that enhanced neutrophil chemotaxis is not only a potential pathogenic mechanism in COPD [7], but might also be a marker for an unfavourable prognosis.

Cigarette smoke exposure leads to enhanced chemotaxis [25], adhesion molecule expression [26] and cytokine release [27] in experimental models. Since cigarette smoking was more prevalent in the chronic bronchitis group, this could have influenced the relationship between chronic bronchitis and neutrophil functions in the context of pneumonia. By multivariate analysis, including disease severity and smoking history, the present authors could eliminate these factors as important contributors to the increased chemotactic activity of systemic PMN in CAP patients with chronic bronchitis.

The current finding of a decreased PMN apoptosis rate of CAP patients with chronic bronchitis may be related to the enhanced chemotactic activity, since apoptosis is associated with impaired effector functions, including chemotaxis, which may be explained by changes in cytoskeleton proteins [28]. Although CXCL-8 is known to delay spontaneous and tumour necrosis factor (TNF)- $\alpha$-mediated apoptosis of PMN [29], no association between CXCL-8 levels and neutrophil apoptosis was found in the present study, which may be due to the fact that numerous other mediators contribute to the balance of pro-apoptotic and anti-apoptotic factors in vivo [30, 31]. In this context, AoshiBA et al. [32] found that nicotine prolonged neutrophil survival in a dosedependent fashion. This effect was associated with the preservation of neutrophil functions, such as chemotaxis and oxygen free-radical generation and may be mediated by noncholinergic receptors on neutrophils.

In the subgroup of patients that were bronchoscopied, elevated local CXCL-8 levels were found corresponding to increased sputum and bronchoalveolar lavage fluid (BALF) concentrations described in COPD patients [8]. The increased intracellular CXCL-8 expression of PMN is in line with in vitro data showing that PMN are able to enhance CXCL- 8 generation in an autocrine/paracrine manner [9]. DUNICAN et al. [13] described higher amounts of CXC chemokines, produced by PMN after stimulation with the same mediators in vitro, compared to concentrations measured in the BALF of patients with acute respiratory distress syndrome or pneumonia. Interestingly, the current authors found an inverse relationship between the activation status of pulmonary PMN, as determined by the surface expression of CD11b, and intracellular CXCL-8 expression, suggesting that in activated cells a higher proportion of intracellularly stored chemokine had already been released.

In contrast to increased local CXCL-8 concentrations, the expression of both CXCL-8 receptors on pulmonary neutrophils was maximally decreased. This finding corresponds to observations in patients with chronic airway inflammation
[33]. The receptor downregulation observed in the present study was most pronounced with regard to CXCR-2, which is well known as a transient desensitisation phenomenon after short-term stimulation with CXCL-8 or lipopolysaccharide (LPS) in vitro [34]. It has been proposed that CXCR-2 is the first receptor receiving the CXCL-8 signal at picomolar range and initiating the migration of neutrophils towards the inflammatory area, whereas CXCR-1 is the major signalling receptor in inflamed tissues with higher ligand concentrations, since CXCR-2 is rapidly and continually internalised. However, this scenario is in contrast to recent findings of high CXCR-2 (and to a lesser extent CXCR-1) expression in the bronchial mucosa during COPD exacerbations [35]. Conversely, the presented data demonstrating a marked downregulation of both $\mathrm{CXC}$ receptors in acute pneumonia suggest that, under prolonged stimulation in vivo, a desensitisation of both receptors may occur at least in the airway lumen. This could be facilitated by the influence of co-stimuli, such as LPS, TNF- $\alpha$, fMLP and complement C5a, which may contribute to the downmodulation of CXCRs by various mechanisms as internalisation, shedding or reduced transcription [34]. The consequences of ligand-induced downmodulation and subsequent re-expression of CXCR-1 and CXCR-2 are unclear. Some observations suggest that receptor endocytosis may be associated with CXCL-8-directed migration of neutrophils [36], whereas a recent study found no relation between internalisation and chemotactic activity [12]. This corresponds to the current authors' inability to find an association between CXCR expression and chemotactic activity.

Unfortunately, due to the limited cell number available, the authors were not able to assess the neutrophil apoptosis rate in the lung, which may be different from circulating cells in inflammatory lung diseases based on previous findings from our group and other authors [14].

In conclusion, the enhanced chemotactic activity of neutrophils in patients with chronic bronchitis and community-acquired pneumonia, combined with prolonged neutrophil survival, indicates that an increased inflammatory response is ongoing in these patients during acute pneumonic episodes. This finding may be prognostically relevant, regarding the association between chemotactic activity and the pneumonia severity index. In addition, an increased activation state of pulmonary neutrophils was found together with elevated local levels of interleukin-8 and downregulated $\mathrm{CXC}$ receptors. The functional consequences of the exaggerated neutrophil response and the altered chemokine receptor expression in the lung remain to be elucidated.

\footnotetext{
Acknowledgements. The authors are indebted to T. Schaefer (Institute of Social Medicine, University of Luebeck, Luebeck, Germany) for statistical assistance.
}

\section{References}

1. Kessler R, Faller M, Fourgaut G, Mennecier B, Weitzenblum E. Predictive factors of hospitalization for acute exacerbation in a series of 64 patients with chronic obstructive pulmonary disease. Am J Respir Crit Care Med 1999; 159: 158-164.

2. Miravitlles $\mathrm{M}$, Espinosa $\mathrm{C}$, Fernández-Laso $\mathrm{E}$, et al. Relationship between bacterial flora in sputum and functional impairment in patients with acute exacerbation of COPD. Chest 1999; 116: 40-46.

3. Inoue $\mathrm{S}$, Nakamura $\mathrm{H}$, Otake $\mathrm{K}$, et al. Impaired pulmonary inflammatory responses are a prominent feature of 
streptococcal pneumonia in mice with experimental emphysema. Am J Respir Crit Care Med 2003; 167: 764-770.

4. Burnett D, Chamba A, Hill SL, Stockley RA. Neutrophils from subjects with chronic obstructive lung disease show enhanced chemotaxis and extracellular proteolysis. Lancet 1987; 7: 1043-1046.

5. Stockley RA, Grant RA, Llewellyn-Jones CG, Hill SL, Burnett D. Neutrophil formyl-peptide receptors. Relationship to peptide-induced response and emphysema. $\mathrm{Am}$ J Respir Crit Care Med 1994; 149: $464-468$.

6. Qiu Y, Zhu J, Bandi V, et al. Biopsy neutrophilia, neutrophil chemokine and receptor gene expression in severe exacerbations of chronic obstructive pulmonary disease. Am J Respir Crit Care Med 2003; 168: 968-975.

7. Beeh KM, Kornmann O, Buhl R, Culpitt SV, Giembycz MA, Barnes PJ. Neutrophil chemotactic activity of sputum from patients with COPD. Role of interleukin 8 and leukotriene B4. Chest 2003; 123: 1240-1247.

8. Richman-Eisenstat JBY, Jorens PG, Hébert CA, Ueki I, Nadel JA. Interleukin-8: an important chemoattractant in sputum of patients with chronic inflammatory airway diseases. Am J Physiol 1993; 264: L413-L418.

9. Atta-ur-Rahman, Harvey K, Siddiqui RA. Interleukin-8: an autocrine inflammatory mediator. Curr Pharm Des 1999; 5: 241-253.

10. Grob PM, David E, Warren TC, DeLeon RP, Farina PR, Homon CA. Characterization of receptor for human monocyte-derived neutrophil chemotactic factor /interleukin8. J Biol Chem 1990; 265: 8311-8316.

11. Schumacher C, Clark-Lewis I, Baggiolini M, Moser B. Highand low-affinity binding of GROa and neutrophil-activating peptide 2 to interleukin-8 receptors on human neutrophils. Proc Natl Acad Sci USA 1992; 89: 10542-10546.

12. Richardson RM, Marjoram RJ, Barak LS, Snyderman R. Role of the cytoplasmic tails of CXCR1 and CXCR2 in mediating leukocyte migration, activation, and regulation. J Immunol 2003; 170: 2904-2911.

13. Dunican A, Grutkoski P, Leuenroth S, Ayala A, Simms HH. Neutrophils regulate their own apoptosis via preservation of CXC Receptors. J Surg Res 2000; 90: 32-38.

14. Droemann D, Aries SP, Hansen F, et al. Decreased apoptosis and increased activation of alveolar neutrophils in bacterial pneumonia. Chest 2000; 117: 1679-1684.

15. Pugin J, Auckenthaler R, Mili N, Janssens JP, Lew PD, Suter PM. Diagnosis of ventilator-associated pneumonia by bacteriologic analysis of bronchoscopic and nonbronchoscopic "blind" bronchoalveolar lavage fluid. Am Rev Respir Dis 1991; 143: 1121-1128.

16. Fine MJ, Auble TE, Yealy DM, et al. A prediction rule to identify low-risk patients with community-acquired pneumonia. $N$ Engl J Med 1997; 336: 243-250.

17. Le Gall JR, Lemeshow S, Saulnier F. A new simplified acute physiology score (SAPS II) based on a european/north american multicenter study. JAMA 1993; 270: 2957-2963.

18. Venaille TJ, Misso NLA, Phillips MJ, Robinson BWS, Thompson PJ. Effects of different density gradient separation techniques on neutrophil function. Scand J Clin Lab Invest 1994; 54: 385-391.

19. Ludwig A, Petersen F, Zahn S, et al. The CXC-chemokine neutrophil-activating peptide-2 induces two distinct optima of neutrophil chemotaxis by differential interaction with interleukin-8 receptors CXCR-1 and CXCR-2. Blood 1997; 90: 4588-4597.

20. Wenisch C, Patruta S, Daxbock F, Krause R, Horl W. Effect of age on human neutrophil function. J Leukoc Biol 2000; 67: 40-45.

21. McLaughlin B, O'Mallay K, Cotter TG. Age-related differences in granylocytochemiotaxis and degranulation. Clin Sci (Lond) 1986; 70: 59-62.

22. Niwa Y, Kasama T, Miyachi Y, Kanoh T. Neutrophil chemotaxis, phagocytosis and parameters of reactive oxygen species in human ageing: cross sectional and longitudinal studies. Life Sci 1989; 44: 1655-1664.

23. Matheson M, Rynell A, McClean M, Berend N. Cigarette smoking increases neutrophil formyl methionyl leucyl phenylalanine receptor numbers. Chest 2003; 123: 16421646.

24. Cummings CJ, Martin TR, Frevert CW, et al. Expression and function of the chemokine receptors CXCR1 and CXCR2 in sepsis. J Immunol 1999; 162: 2341-2346.

25. Totti N III, McCusker KT, Campbell EJ, Griffin GL, Senior RM. Nicotine is chemotactic for neutrophils and enhances neutrophil responsivness to chemotactic peptides. Science 1983; 223: 169-171.

26. Klut ME, Doerschuk CM, Van Eeden SF, Burns AR, Hogg JC. Activation of neutrophils within pulmonary microvessels of rabbits exposed to cigarette smoke. Am J Respir Cell Mol Biol 1993; 9: 82-89.

27. Morrison D, Strieter RM, Donnelly SC, Burdick MD, Kunkel SL, MacNee W. Neutrophil chemokines in bronchoalveolar lavage fluid and leukocyte-conditioned medium from nonsmokers and smokers. Eur Respir J 1998; 12: 1067 1072.

28. Kobayashi SD, Voyich JM, Braughton KR, DeLeo FR. Down-regulation of proinflammatory capacity during apoptosis in human polymorphnuclear leukocytes. J Immunol 2003; 170: 3357-3368.

29. Kettritz R, Gaido ML, Haller H, Luft FC, Jennette CJ, Falk RJ. Interleukin-8 delays spontaneous and tumour necrosis factor-a-mediated apoptosis of human neutrophils. Kidney Int 1998; 53: 84-91.

30. Colotta F, Re F, Polentarutti N, Sozzani S, Mantovani A. Modulation of granulocyte survival and programmed cell death by cytokines and bacterial products. Blood 1992; 80: 2012-2020.

31. Girard D, Paquet ME, Paquin R, Beaulieu AD. Differential effects of interleukin-15 (IL-15) and IL-2 on human neutrophils: modulation of phagocytosis, cytoskeleton rearrangement, gene expression, and apoptosis by IL-15. Blood 1996; 88: 3176-3184.

32. Aoshiba K, Nagai A, Yasui S, Konno K. Nicotine prolongs neutrophils survival by suppressing apoptosis. J Lab Clin Med 1996; 127: 186-194.

33. Soejima K, Fujishima S, Nakamura H, et al. Downmodulation of IL-8 receptors, type A and type B, on human lung neutrophils in vivo. Am J Physiol 1997; 273: L618-L625.

34. Khandaker MH, Mitchel G, Xu L, et al. Metalloproteinases are involved in lipopolysaccharide- and tumour necrosis factor- $\alpha$-mediated regulation of CXCR 1 and CXCR2 chemokine receptor expression. Blood 1999; 93: 2173-2185.

35. Qiu Y, Zhu J, Bandi V, et al. Biopsy neutrophilia, neutrophil chemokine and receptor gene expression in severe exacerbations of chronic obstructive pulmonary disease. Am J Respir Crit Care Med 2003; 168: 968-975.

36. Yang W, Wang D, Richmond A. Role of clathrin-mediated endocytosis in CXCR2 sequestration, resensitization, and signal transduction. J Biol Chem 1999; 274: 11328-11333. 